\title{
Strategic thinking as a factor of sustainable development of the organization
}

\author{
Evgeniy Bikmetov ${ }^{1,2, *}$, Natalya Galimullina ${ }^{3}$, Igor Ruvenny ${ }^{1}$, Zarina Sizonenko ${ }^{3}$, and \\ Roman Sizonenko ${ }^{2}$ \\ ${ }^{1}$ Ufa State Aviation Technical University, K. Marx str., 12, 450008 Ufa, Russia \\ ${ }^{2}$ Institute of Social and Economic Researches, separate structural unit of the Federal State Budgetary \\ Scientific Institution of the Ufa Federal Research Center of the Russian Academy of Science, Ave. \\ October, 54, 450054 Ufa, Russia \\ ${ }^{3}$ Bashkir State University, Z. Validi str., 32, 450076 Ufa, Russia
}

\begin{abstract}
The article reveals the methodological foundations of the effective staff training and identifies the influence directions of organizational training on the strategic thinking formation. In the changing world in which crises become a natural phenomenon and the long-term planning is difficult, strategic thinking is actualized. Strategic thinking is based on the ability to interact with future, understand the changes and transform it into concrete strategic actions. Result of overcoming the crisis is determined by the ability of the company's management to find the right balance between defensive strategies aimed at preserving the results of the past, and offensive strategies focused on using of the opportunities for development. The authors propose an understanding of strategic thinking as an actual activity of the subject of management, motivated by organizational needs and values, aimed at determining the general path of sustainable movement to the long-term goals taking into account the dynamism and uncertainty of the environment, the changing ratio of expected long-term benefits and costs; a system of competence indicators "strategic thinking" has been developed; the possibility of organizational training in the formation of such competence as strategic thinking has been substantiated.
\end{abstract}

\section{Introduction}

The modern management concept comes from the key employee role, his innovative creativity in all business processes. The task of creating a staff development system, contributes to the formation of key competencies, the self-realization of employees, the harmonization of their interests with the strategic interests of the organization is actualized.

However, the potential of organizational training is not fully used in spite of the significant heuristic content of the approach itself. The objectives of this study are:

- disclosure of the methodological foundations of effective staff training in the knowledge management system in the company,

\footnotetext{
${ }^{*}$ Corresponding author: bicprof@mail.ru
} 
- substantiation of the organizational learning opportunities in the formation of such competence as strategic thinking,

- determination of the relation between the competence of strategic thinking and the sustainable organizational development.

\section{Literature review and methods}

The foundations for studying the corporate knowledge application and training in corporate management were laid in the works of P. Senge, I. Nonaki, H. Takeuchi $[1,2]$, where organizational training is seen as a continuous cognition of the new methods of interaction with the environment. The intellectual capital of organization is located in the interdisciplinary research field [3-7]. Conceptual foundations of knowledge management, corporate training and self-training, learning organization are studied in works [8-13]. Learning process in organizations is associated with strategic management [14]. P. Senge distinguishes among the technologies implemented in learning organizations: individual improvement, creating a shared vision, team training through the dialogue communication, formation a system thinking [1]. These provisions serve as a methodological guideline of the training process design in the corporate knowledge system.

The methodology of the study conducted by the authors includes a number of specific methods and concepts:

- the objectivity principle, which implies a comprehensive account of the factors underlying the studying phenomenon;

- the consistency principle, which allows to present the management of the corporate educational process and knowledge as a complex, open, dynamically developing system;

- the essential analysis principle, associated with the disclosure of the patterns of complex social and economic systems and relationships, the key factors of their development, the possibility of their purposeful change;

- the behavioral and cognitive approach principles in studying the formation of strategic thinking and staff knowledge management;

- $\quad$ the postpositivist approach to the study of M. Polani's knowledge [5];

- $\quad$ sustainable organizational development principles [15].

The following methods are used:

- applied methods of the author's social research [16], including observation, expert survey, a survey of target groups;

- $\quad$ secondary data analysis from a survey of 460 CEOs of Russian companies [17];

- secondary data analysis of empirical research of 1,000 companies belonging to small and medium businesses in Germany, Austria and Switzerland [18].

\section{Results and Discussion}

The formation of staff development is vocational training. The man, mastering the competencies required for management activities, comes into communication not only with the direct subject-bearer of modern knowledge, but also indirectly from the previous generation, having a set of corporate application knowledge (experience). Such communication can be carried out, if an employee has developed an attitude towards the production of innovative ideas. But innovation is associated with the ability to be creative, the release of human thinking beyond the limited functionality. The training efficiency is also determined by the extent to which the set goals are internalized by the man. Knowledge can arise and be transmitted in interpersonal relationships involving the development of a spirit of trust and mutually responsible partnership. One of the tasks of 
ensuring the training process efficiency is the acquaintance of students with the processes of the corporate knowledge genesis, which involves including the forecasting of these situations, when the man in the training process, not finding a known way of obtaining information, begins to develop new knowledge. Knowledge is not only transformed into an activity program, but also becomes the conviction of the man or a work group.

In management staff, intellectual activity is manifested in the development of strategic thinking. In the changing world with high risk, the long-term planning is difficult and strategic thinking comes to its rescue. It is based on the ability to interact with the future, to understand the changes and transform them into a strategic action. Strategic management imposes on managers a number of requirements: the ability to model a situation; the ability to identify the need for change; the ability to develop a change strategy in the organization; the ability to use the safe methods in the course of strategic change; the ability to translate the strategy into reality. In other words, strategic thinking in management is the key to the success of the leader and his team.

The data from a survey of 460 CEOs of Russian companies [17] indicate that in the near future, "strategic vision of business development" will occupy the first position on the scale of qualities. These data partially overlap with the results of research into the social problems of management relations in industrial enterprises conducted in the Republic of Bashkortostan in 2011 and 2014 [16]. A large number of choices received the qualities that form the strategic thinking formation: "responsibility" (65.5\%), "focus on results" (52.4\%), "flexibility and high intelligence" (39\%). But to the question: "Is it true that the involvement of employees in your company, the use and development are carried out purposefully and thoughtfully, in accordance with its mission, long-term goals of the organization?" received conflicting answers.

Table 1. Compliance assessment of the use and staff development with strategic goals.

\begin{tabular}{|c|c|c|c|}
\hline № p/p & Possible answer & Staff management (\%) & Workers (\%) \\
\hline 1 & That's right & 20 & 3 \\
\hline 2 & Rather right than wrong & 20 & 17 \\
\hline 3 & Rather wrong than right & 53 & 24 \\
\hline 4 & That's wrong & 7 & 50 \\
\hline 5 & Difficult to answer & 0 & 6 \\
\hline
\end{tabular}

An analysis of survey results showed that staff development is rather spontaneous than purposeful and does not coincide with strategic goals. Therefore, in organizational training and education management reserve in conditions of uncertainty and risk, the need for the formation of a creatively thinker is actualized because innovation serves as the targeted implementation of the potential that is contained in the creativity inherent in the innovative type of a manager personality.

Are of some interest the results of research [18] where strategic management is defined as the desire to prepare for future opportunities, provide the environment dynamic. The essence of the research hypothesis is to prepare for the future, not only to anticipate it. The survey was conducted in 1000 companies belonging to small and medium businesses in Germany, Austria and Switzerland. As a result, it was revealed that the planning (although highly valued) is not as widely used in small and medium-sized businesses, because it is not 
enough time. However, the researchers didn't find a direct connection between strategic planning and the future company success. Similar studies were conducted in the 80 s of the twentieth century. It was concluded that the company is larger, the more likely the presence of strategic planning. Small companies can't allow this. Therefore, it is not surprising that representatives of small and medium-sized businesses generally have a negative attitude towards planning, arguing that strategic tools destroy their ability to improvise; in addition, the planning takes time. Usually this attitude is explained by the lack of sufficient knowledge in the field of business and revaluation of its opportunities. On the other hand, the respondents believe that the small size of firms gives them flexibility and allows them to specialize in certain niches. But has something changed since the past? Despite the fact that $75 \%$ of companies believe the planning is important, half of them do not use this method. About $63 \%$ of smaller companies have no plans to operate, compared with $12 \%$ of larger companies. The availability of planning also depends on whether the owner controls the company, as in such companies the planning probability is very low. The researchers tried to identify the key motivators and barriers in the way of strategic planning. $89 \%$ of respondents believe that the planning would help the corporate income. But more than half of the companies who do not plan, said that they simply do not have experience in this field. The main explanation was the lack of time - managers believe that this process is less necessary compared to the daily business. Some items of research have revealed a direct link between the planning and corporate success, most researchers and experts view the strategic planning as a positive experience. Could not find a direct link between the use of strategic planning and profitability or rise in incomes. In addition, the authors of the study insist on the need for strategic planning and argue that it is likely that small and medium businesses need special tools that would facilitate the use of planning.

There is a position about the difficulty of adopting a strategy for pursuing a goal in the realities of the Russian market. Its supporters claim that the "strategy is the ambitious fantasy, on the verge of utopia or an utopia" [19]. There is a contrast between the tactical and strategic management and, accordingly, the qualities required of the management subjects. In their opinion, such important properties as flexibility, openness, and innovation are inherent in the thinking only of managers who know how to use small tactical opportunities for a quick victory on the market. The understanding of the strategy and content of strategic thinking that contributes to the sustainable development of an organization, presented by the authors of the article, comes into some conflict with the position of tactically oriented researchers.

\section{Conclusions}

According to the authors, strategic thinking is the actual activity of the management subject, motivated by organizational needs and values, aimed at determining the general path of sustainable movement to the long-term goals taking into account the dynamism and uncertainty of the environment, the changing ratio of expected long-term benefits and costs.

On the basis of competence approach in the evaluation of management quality, the strategic thinking indicators are proposed, distributed over four levels.

1. Initial level (understanding and analysis of its organization's strategy; aligning its actions with the long-term goals and organization's strategy; understanding the strategy of the main competitors; lack of personal involvement in strategy development).

2. Basic level (understanding of the problem areas and opportunities; participation in the development of the organization's strategy; competent evaluation and selection of own actions; analysis of its actions and their consequences; the ability to minimize the risks).

3. Advanced level (understanding of the impact of external factors on strategy; participation in the development of the organization's strategy; considering the development 
of events in the long term; understanding the relationship between external and internal environment; develop the innovative views on the solution of problems).

4. Master level (creation of the organization's competitive strategies; making significant changes in activity; forecasting the long-term development of significant events; develop the scripts in case of strategic surprises).

The signs of the selected indicators can be the results presented in Table 2.

Table 2. Competence indicator system "Strategic thinking" for assessment the sustainability of corporate development.

\begin{tabular}{|c|c|c|c|}
\hline Indicators & Signs & Sign purpose & Result \\
\hline \multirow{2}{*}{$\begin{array}{c}\text { 1. Initial } \\
\text { level }\end{array}$} & $\begin{array}{c}\text { Level of awareness about } \\
\text { competitive situation }\end{array}$ & $\begin{array}{c}\text { Competitiveness } \\
\text { assessment of the } \\
\text { organization }\end{array}$ & $\begin{array}{c}\text { Ensuring of the } \\
\text { organization } \\
\text { survival }\end{array}$ \\
\cline { 2 - 4 } & $\begin{array}{c}\text { Target performance signs of } \\
\text { the organization }\end{array}$ & $\begin{array}{c}\text { Assessment the efficiency } \\
\text { of strategy implementation }\end{array}$ & Cost optimization \\
\hline \multirow{2}{*}{$\begin{array}{c}\text { 2. Basic } \\
\text { level }\end{array}$} & Strategy risk level & Risk management & Risk minimization \\
\cline { 2 - 5 } & Financial sustainability & $\begin{array}{c}\text { Identifying the financial } \\
\text { sustainability issues }\end{array}$ & $\begin{array}{c}\text { Growth the } \\
\text { financial } \\
\text { sustainability }\end{array}$ \\
\hline \multirow{3}{*}{$\begin{array}{c}\text { 3. Advanced } \\
\text { level }\end{array}$} & Benchmarking quality & \begin{tabular}{c} 
Selection of effective \\
competitors for comparison \\
\cline { 2 - 5 }
\end{tabular} & $\begin{array}{c}\text { Obtaining and } \\
\text { using the best } \\
\text { practices }\end{array}$ \\
\hline \multirow{2}{*}{$\begin{array}{c}\text { and external environment } \\
\text { Master }\end{array}$} & Market share & $\begin{array}{c}\text { Adjustment of the } \\
\text { development strategy }\end{array}$ & $\begin{array}{c}\text { Sustainable } \\
\text { development }\end{array}$ \\
\cline { 2 - 5 } & Investment potential & $\begin{array}{c}\text { Sustainable development } \\
\text { perspectives }\end{array}$ & $\begin{array}{c}\text { Capitalization } \\
\text { growth }\end{array}$ \\
\hline
\end{tabular}

Thus, the focus of the corporate educational process should focus on ensuring that employees think systematically and strategically. In addition, each participant of the educational process is able to reveal the further personal trajectory of mastering the basics of strategic thinking. In learning organization all management decisions in relation to internal business processes, methods and means of its tactics and business strategy must be considered an object of joint critical reflection and reflection.

\section{References}

1. P.M. Senge, The Fifth Discipline: The Art and Practice of the Learning Organization (1990)

2. I. Nonaka, Kh. Takeuchi, The Knowledge - Creating Company: How Japanese Companies Create the Dynamics of Innovation (2003)

3. A.L. Gaponenko, T.M. Orlova, Knowledge management. How to Turn Knowledge into Capital (2008)

4. T.A. Stewart, Intellectual Capital: The New Wealth of Organizations (1997)

5. M. Polanyi, Personal Knowledge: Towards a Post-critical Philosophy (1962)

6. A. Brooking, Intellectual Capital: The Key to Success in the New Millennium (2009)

7. J.J. Hoffman, M.L. Hoelscher, K. Sherif, Journal of Knowledge Management, 9(3), 93 (2005) 
8. H. de J.G. Antunesa, P.G. Pinheiro,. Journal of Innovation \& Knowledge, 5(3), 176 (2020)

9. Z. Erden, D. Klang, R. Sydler, G. von Krogh, Journal of Business Research, 67(1), 2777 (2014)

10. J. Giniuniene, L. Jurksiene, Dynamic Capabilities, Procedia-Social and Behavioral Sciences, 213, 985 (2015)

11. R.M. Grant, Strategic Management Journal, 17(S2), 109 (1996)

12. A. Jain, A. Moreno, Learning Organization, 22/1, 14 (2015)

13. J. Nieves, A. Quintana, J. Osorio, Knowledge Management Research \& Practice, 14(3), 237 (2016)

14. O.S. Vikhanskiy, Strategic management: textbook (2003)

15. R.L. Ackoff, J. Magidson, H.J. Addison, Idealized Design. Creating an Organization's Future (2006)

16. E.Yu. Bikmetov, Sotsiologicheskie Issledovaniia, 9, 69 (2014)

17. Kommersant, https://www.kommersant.ru/doc/351440

18. S. Kraus, B.S. Reiche, C.H. Reschke, Implications of Strategic Planning in SMEs for International Entrepreneurship Research and Practice. In.: Energizing Management Through Innovation and Entrepreneurship (2008)

19. M. Rozin, Success without strategy: Flexible Management Technologies (2011) 